\title{
Resposta tecidual ao compósito $50 \%$ hidroxiapatita: $50 \%$ poli-hidroxibutirato para substituição óssea em coelhos
}

[Tissue response to the composite 50\% hydroxyapatite: 50\% polyhydroxybutyrate for bone substitution in rabbits]

\author{
E.C. Carlo ${ }^{1}$, A.P.B. Borges ${ }^{1}$, M.I.V. Vargas $^{1}$, M.M. Martinez ${ }^{2}$, R.B. Eleotério ${ }^{1}$, \\ A.R. Dias ${ }^{1}$, M.C.D. Rodrigues ${ }^{1}$ \\ ${ }^{1}$ Departamento de Veterinária - UFV \\ Av. P. H. Rolfs, s/n. \\ 36570-000 - Viçosa, MG \\ ${ }^{2}$ Universidade de Córdoba - Colômbia
}

\begin{abstract}
RESUMO
Avaliaram-se a biocompatibilidade, a osseointegração, a osseocondução e a biodegradação de compósitos de $50 \%$ hidroxiapatita (HAP-91®) e 50\% poli-hidroxibutirato. O compósito foi implantado em defeitos ósseos em 12 coelhos (grupo experimental), sendo comparado a defeitos não preenchidos (grupo-controle, de igual número). Os parâmetros clínicos dor, claudicação, infecção, deiscência e edema foram avaliados nos primeiros oito dias após a cirurgia e aos 45 e 90 dias. Radiografias foram realizadas aos oito, 45 e 90 dias após a cirurgia em quatro animais por grupo que, em seguida, foram submetidos à eutanásia para coleta de amostras destinadas a análises histológica e histomorfométrica. Não ocorreram diferenças entre os grupos para todos os parâmetros clínicos. Radiografias demonstraram um compósito com radiopacidade semelhante à do osso vizinho e contato direto entre osso e compósito aos 45 e 90 dias. Diferença significativa foi observada entre a porcentagem dos tecidos ósseo e conjuntivo dentro do defeito nos dias oito, 45 e 90, assim como na interface aos 45 e 90 dias. Foram observadas projeções dos tecidos ósseo e conjuntivo no interior do compósito e sinais de biodegradação na ausência de infiltrado inflamatório. Pode-se concluir que o compósito é biocompatível, osseocondutor, biodegradável e se integra ao tecido ósseo.
\end{abstract}

Palavras-chave: coelho, biomateriais, substituto ósseo, compósito

\begin{abstract}
The biocompatibility, osseointegration, osseoconductivity, and biodegradation of a 50-50\% hydroxyapatite (HAP-91®)-polyhydroxybutyrate were evaluated. The composite was implanted in bone defects of 12 rabbits (experimental group), being compared to unfilled defects (control group, 12 animals). The clinical parameters of pain, lameness, infection, dehiscence, and edema were evaluated during the first eight days and on the $45^{\text {th }}$ and $90^{\text {th }}$ days after surgery. Radiographs were taken in four animals per group at 8, 45, and 90 days after surgery, when animals were euthanized to collect samples for histology and histomorphometry. Significant differences between groups for all clinical parameters were not observed. Radiographs showed a similar radiopacity of the composite and bone and their direct contact. More bone than connective tissue was found within the defect at 8, 45, and 90 days and at the interface on the $45^{\text {th }}$ and $90^{\text {th }}$ days. Projections of bone and connective tissue were seen inside the composite. Biodegradation signs became evident, with absence of inflammatory infiltrate. Data support that such composite is biocompatible, osseoconductive, biodegradable, and integrate to bone.
\end{abstract}

Keywords: rabbit, biomaterials, bone substitute, composite

\section{INTRODUÇÃO}

A perda de tecido ósseo é um importante desafio para a medicina e odontologia humanas e

Recebido em 28 de dezembro de 2008

Aceito em 9 de julho de 2009

E-mail: emilycarlo@yahoo.com.br veterinárias, pois resulta em defeitos que necessitam de auxílio para uma adequada regeneração e restabelecimento das funções locais. Diversas afecções podem originar tais defeitos, sendo a principal delas as fraturas 
cominutivas, mas também a necessidade de retirada de tecido neoplásico e a reabsorção do osso alveolar na odontologia (Brandão et al., 2002; Kleiner e Silva, 2003; Walsh et al., 2003).

A associação de uma cerâmica a um polímero foi sugerida para a substituição do tecido ósseo, possibilitando a fabricação de implantes em tamanhos e formas apropriados para cada paciente (Doyle et al., 1991; Luklinska e Bonfield, 1997; Scarano et al., 2006; Shishatskaya et al., 2006). Esse material tem por função ocupar o defeito, mantendo a redução apropriada e a continuidade dos fragmentos, servindo como suporte para a regeneração do tecido ósseo que gradativamente o substituirá (Boer et al., 2003).

Dessa forma, o presente trabalho teve o objetivo inicial de analisar a biocompatibilidade, a osseointegração, a osseocondução e a biodegradação do compósito, associando a hidroxiapatita sintética HAP-91 ${ }^{\circledR}$ ao polihidroxibutirato, e o objetivo final de disponibilizar um substituto ósseo de preço mais acessível do que os hoje existentes no mercado brasileiro, já que este material foi desenvolvido com matéria prima e tecnologia nacionais.

\section{MATERIAL E MÉTODOS}

Este trabalho foi aprovado pela Comissão de Ética do DVT/UFV, em consonância com o estabelecido pelo Colégio Brasileiro de Experimentação Animal.

Os compósitos com $50 \%$ de cada biomaterial, hidroxiapatita sintética ${ }^{1}$ e poli-hidroxibutirato (PHB), fornecidos com um formato retangular, foram cortados de forma asséptica com uma broca trefina de $4 \mathrm{~mm}$ de diâmetro, para adequar o tamanho e o formato dos implantes ao defeito.

Foram utilizados 24 coelhos adultos da raça Nova Zelândia, com pesos entre 3 e 3,5kg, alojados em gaiolas individuais, onde receberam ração duas vezes ao dia e água à vontade. Os coelhos foram distribuídos aleatoriamente em dois grupos com igual número de animais: o grupo-controle (C) e o grupo compósito (HP). Os

${ }^{1}$ HAP $91^{\circledR}$ - JHS Laboratório Químico LTDA. Belo Horizonte, Brasil. animais receberam penicilina $G^{2}$ na dose de $40.000 \mathrm{UI} / \mathrm{kg}$ via intramuscular (IM) 30 minutos antes da cirurgia como terapia antimicrobiana profilática. Eles foram sedados com levomepromazina ${ }^{3}(2 \mathrm{mg} / \mathrm{kg}, \mathrm{IM})$ e anestesiados com associação de tiletamina-zolazepam ${ }^{4}$ $(30 \mathrm{mg} / \mathrm{kg}$, IM). Os membros torácicos foram tricotomizados desde a região proximal da diáfise do úmero até o carpo e, após antissepsia, utilizou-se lidocaína $2 \%{ }^{5}(1,5 \mathrm{ml})$ para realização de bloqueio anestésico do plexo braquial.

Foi realizada incisão curva de pele na superfície lateral da articulação úmero-rádio-ulnar. O músculo tríceps braquial foi afastado, expondo a cortical lateral do olécrano. Foi confeccionada uma falha óssea circular de $4 \mathrm{~mm}$ de diâmetro, com o auxílio de uma broca trefina ${ }^{6}$, acoplada a uma perfuratriz elétrica sob irrigação com solução de $\mathrm{NaCl}$ 0,9\%. Os defeitos dos animais do grupo HP foram preenchidos com o compósito. Os defeitos dos animais do grupo $\mathrm{C}$ não foram preenchidos. Os tecidos foram aproximados utilizando-se fio não-absorvível de náilon ${ }^{7}$. Os cuidados pós-operatórios incluíram a administração de morfina ${ }^{8}$ a cada seis horas, por três dias $(2 \mathrm{mg} / \mathrm{kg}, \quad \mathrm{IM})$, e penicilina $^{9}$ (40.000UI/kg, IM) a cada 24 horas, por dois dias.

Imediatamente após a cirurgia, radiografias foram realizadas nas posições mediolateral, com a articulação úmero-rádio-ulnar flexionada $\mathrm{e}$ tangencial ao olécrano. Nesta última, o animal foi posicionado em decúbito dorsal com o úmero paralelo à mesa e a articulação úmero-rádio-ulnar em total flexão.

As avaliações clínicas foram realizadas diariamente nos primeiros oito dias e depois, aos 45 e 90 dias. Cada membro foi avaliado quanto à claudicação, de acordo com o apoio da extremidade do membro com os escores: 0 - sem claudicação; 1 - apoio com claudicação; 2 -

${ }^{2}$ Megacilin ${ }^{\circledR}$ - União Química Farmacêutica Nacional S/A São Paulo, Brasil.

${ }^{3}$ Neozine ${ }^{\circledR}$ - Sanofi-aventis - São Paulo, Brasil

${ }^{4}$ Zoletil 50® - Farmavet Produtos Veterinários Ltda. - São Paulo, Brasil

${ }^{5}$ Lidocaína 2\%- Hipolabor - Sabará, Brasil.

${ }^{6}$ Neodent ${ }^{\circledR}$ - Curitiba, Brasil.

${ }^{7}$ Monofilamento preto Nylon 3-0 Technofio- Farma Brasileira - São Paulo, Brasil.

${ }^{8}$ Dimorf $^{\mathbb{R}}$ - Cristália do Brasil - Itapira-SP, Brasil.

${ }^{9}$ Megacilin ${ }^{\circledR}$ - União Química Farmacêutica Nacional S/A. São Paulo, Brasil. 
ausência completa de apoio. A ferida cirúrgica foi avaliada quanto à presença de deiscência, infecção e reação inflamatória, esta última analisada pelos parâmetros edema e dor. O edema foi avaliado quantitativamente pela mensuração da circunferência do membro no local da ferida cirúrgica. A sensibilidade dolorosa foi avaliada pela reação do animal ao toque da ferida cirúrgica e flexão e extensão da articulação úmero-rádio-ulnar, atribuindo-se os escores: 0 - quando não existiu qualquer manifestação do animal; 1 - houve retração do membro sem outra manifestação; 2 - houve retração do membro associada à vocalização ou tentativa de fuga. A deiscência de sutura foi avaliada em presente ou ausente, assim como a infecção da ferida cirúrgica, observada pela presença de secreção purulenta proveniente do local.

Nos dias oito, 45 e 90 após a cirurgia, foram realizadas radiografias de quatro animais de cada grupo, repetindo os posicionamentos realizados no pós-operatório imediato. As radiografias foram analisadas quanto à presença de reação periosteal, esclerose e reabsorção óssea. Foi confeccionado um esquema em folha transparente que, sobreposto às radiografias, dividiu o defeito em quatro quadrantes. Isso permitiu analisar e classificar a radiopacidade de cada quadrante em menor, semelhante ou maior do que a do osso vizinho, observar as bordas do defeito/compósito em cada quadrante e verificar se o limite entre osso e compósito podia ser bem delimitado.

Quatro animais de cada grupo foram submetidos à eutanásia com sobredose anestésica ${ }^{10}$, em cada um dos dias oito, 45 e 90 após a cirurgia. Então, foram coletadas amostras do olécrano contendo o defeito após ressecção com serra ortopédica para processamento histológico. As amostras foram fixadas em formol $10 \%$ tamponado e, em seguida, descalcificadas em ácido fórmico a $10 \%$ tamponado com citrato de sódio para $\mathrm{pH} 4,5 \mathrm{sob}$ vácuo moderado. Após a descalcificação, as amostras foram seccionadas no sentido transversal ao eixo longo da ulna, no centro do defeito, para se obter a superfície de análise. Então, foram lavadas em água corrente, desidratadas, diafanizadas e incluídas em parafina. Foram obtidos cortes de $5 \mu \mathrm{m}$ de

\footnotetext{
${ }^{10}$ Tiopental® - Cristália. Itapira-SP, Brasil.
}

espessura, corados pelas técnicas de hematoxilina-eosina, tricrômico de Gomori (TG) e azul de toluidina (AT), para posterior análise à microscopia de luz.

À análise histológica (qualitativa), foram caracterizados os tecidos e as células presentes em toda a amostra. À histomorfometria, o número de osteoclastos presentes em 10 campos por amostra foi contado em aumento de $200 \mathrm{X}$ em ambos os grupos. Com auxílio de uma ocular graduada, foram quantificadas percentualmente as estruturas compósito, tecido ósseo, tecido conjuntivo e medula óssea, somente no grupo HP. Realizou-se a caracterização dos tecidos presentes na interface com o compósito, permitindo a obtenção do percentual de tecido ósseo, medula óssea e tecido conjuntivo também com uma ocular graduada, mas contando-se apenas $o$ primeiro ponto de interseção imediatamente após o compósito em cada linha. Para analisar a formação de tecidos dentro do compósito, a mesma ocular graduada foi sobreposta somente no interior do compósito em cinco campos por amostra, procedendo-se à contagem dos pontos.

Os dados clínicos e histomorfométricos foram avaliados estatisticamente, considerando significante um valor de $P$ menor do que 0,05 . As comparações entre os dias dentro de cada grupo foram realizadas utilizando-se $\mathrm{o}$ teste Kruskal-Wallis, seguido pelo teste de comparações múltiplas de Dunn's. Para as variáveis clínicas infecção, claudicação, dor e deiscência, compararam-se os dias um, quatro e oito entre si, dentro de cada grupo. As médias dos números de osteoclastos em cada um dos dias oito, 45 e 90 foram comparadas entre si em cada grupo e, da mesma forma, os valores de porcentagem de tecido ósseo e tecido conjuntivo dentro do compósito. Para comparar os grupos $\mathrm{C}$ e HP, utilizou-se o teste Mann-Whitney. Assim, as variáveis infecção, claudicação, dor e deiscência foram comparadas entre os grupos em cada um dos dias um, quatro e oito após a cirurgia. Da mesma forma, a diferença entre a formação dos tecidos ósseo e conjuntivo no defeito como um todo, na interface com o compósito e dentro do compósito foi avaliada. A variável edema (circunferência do membro) foi avaliada como evolução de um mesmo animal utilizando-se o teste Wilcoxon para amostras não independentes. 


\section{RESULTADOS E DISCUSSÃO}

O compósito mostrou-se macroscopicamente um material compacto e facilmente manipulável durante a cirurgia, apesar de ter se quebrado algumas vezes no momento do corte com a broca trefina. Esta observação está de acordo com os achados de Doyle et al. (1991), que observaram menores valores de resistência à tração e compressão com altas porcentagens de hidroxiapatita em compósitos semelhantes.

A cicatrização da ferida cirúrgica cutânea se completou, em geral, até o sétimo dia. Três animais de cada grupo apresentaram dor grau 1, ocorrendo nos três primeiros dias no grupo $\mathrm{C}$ e no grupo HP nos dois primeiros dias. Infecção não foi observada em nenhum animal. Dois animais de cada grupo apresentaram claudicação grau 1, coincidindo com os dias de dor. Um animal de cada grupo apresentou deiscência devido à interferência na sutura. Não existiu qualquer diferença significante entre os grupos para os parâmetros dor, claudicação, infecção e deiscência, o que indica a biocompatibilidade do compósito e, ainda, que a existência desses sinais se deveu à manipulação cirúrgica e não à presença do biomaterial. Esse resultado está de acordo com estudos anteriores com a hidroxiapatita utilizada em cães e coelhos (Borges et al., 2000; Vital et al., 2006; Sá et al., 2007). A avaliação do edema corrobora com esses resultados, visto que não existiram diferenças significantes entre os grupos, assim como entre os valores do pós-operatório imediato e os dias oito, 45 e 90 . Diferença significante foi observada entre os valores pré-operatórios da circunferência do membro em relação aos valores do primeiro e quarto dias, indicando a existência de aumento de volume em ambos os grupos. Este fato é esperado devido à manipulação cirúrgica do membro (Borges et al., 2000; Vital et al., 2006).

À análise radiográfica, não foram observadas reação periosteal, esclerose ou reabsorção óssea em nenhum dos grupos. Os defeitos do grupocontrole nas radiografias obtidas no pósoperatório imediato e aos oito dias após a cirurgia se caracterizaram por radiopacidade menor do que a do osso vizinho em todos os quadrantes e bordas bem delimitadas. Nas radiografias do grupo HP nestes mesmos dias, foi observado um halo menos radiopaco ao redor do compósito, correspondendo à distância entre a parede do defeito e o compósito, observada durante a cirurgia. Sabe-se que os tecidos moles não são radiopacos devido à ausência da matriz calcificada, correspondendo, após a cirurgia, ao coágulo que se formou neste local e provavelmente aos tecidos moles, conjuntivo ou osteoide, aos oito dias, que participam da regeneração óssea (Yamamuro, 1994; Vital et al., 2006; Sá et al., 2007). O compósito apresenta radiopacidade semelhante à do osso vizinho, justificada pelo teor de hidroxiapatita que possui elementos com alto número atômico em sua constituição, portanto radiopacos (Borges et al., 2000; Duarte et al., 2006).

A avaliação das radiografias do grupo-controle aos 45 dias revelou redução no tamanho do defeito e radiopacidade já semelhante à do osso vizinho em $37,5 \%$ dos quadrantes, indicando a regeneração do defeito em andamento. Aos 90 dias, 58,3\% dos quadrantes tinham radiopacidade semelhante à do osso vizinho e os defeitos apresentavam-se com menor tamanho do que aos oito dias. Esse processo de regeneração óssea mais avançado neste dia, em comparação com os anteriores, era esperado, já que foram realizados defeitos de tamanho não-crítico, ou seja, onde esse processo não é dificultado ou impedido pelo tamanho do defeito (MacNeill et al., 1999).

O halo menos radiopaco do que o osso vizinho presente aos oito dias não foi mais observado aos 45 e 90 dias no grupo HP. Nestes dias, os defeitos haviam diminuído de tamanho e não foi possível delimitar as margens de $50 \%$ dos quadrantes, observando-se o contato direto entre compósito e osso. Essas observações indicam a formação de novo osso nas bordas do compósito, reforçando a biocompatibilidade e indicando a osseointegração. Estes resultados estão de acordo com os achados de Knowles et al. (1992), Luklinska e Bonfield (1997) e Doyle et al. (1991), sendo que estes últimos observaram média de $90 \%$ de aposição direta entre osso e PHB após implantação por seis meses.

Em nenhuma das amostras foi observado infiltrado inflamatório de qualquer tipo celular, o que indica a biocompatibilidade do compósito, corroborando com os dados clínicos e com estudos realizados por Cheng et al. (2006) e Shishatskaya et al. (2006). 
À análise histológica aos oito dias no grupocontrole, pôde-se observar processo típico de regeneração de uma falha óssea. Trabéculas novas - delgadas e numerosas com osteoclastos e grande número de osteoblastos ativos em suas margens - partindo da região medial ao defeito, entremeadas por tecido conjuntivo denso vascularizado. No grupo HP, a arquitetura dos tecidos apresentou-se muito semelhante à do grupo-controle aos oito dias. A interface com o compósito na região medial ao defeito constituiuse principalmente por trabéculas novas (Fig. 1A), mas também por tecido conjuntivo denso vascularizado, estando de acordo com os achados de Doyle et al. (1991). Não foi constatada diferença estatisticamente significante entre as porcentagens dos tecidos ósseo e conjuntivo neste dia. Tecido conjuntivo predominou na interface das regiões distal e proximal ao defeito, e tecido ósseo predominou na região medial ao defeito, provavelmente devido à influência de dois fatores. O primeiro deles é a distância observada durante a cirurgia entre a parede do defeito e o compósito. Essa distância ocorreu devido à utilização da mesma broca para fazer o defeito no osso e o corte do compósito, resultando na retirada do diâmetro externo da broca, ao corte do osso e, do diâmetro interno da broca, ao corte dos compósitos. Tal distância pode permitir a invaginação de tecido conjuntivo no local antes da formação de tecido ósseo (MacNeill et al., 1999). O segundo é a presença de grande quantidade de medula óssea na região medial ao defeito, origem de células osteoprogenitoras (Sá et al., 2007) responsáveis pela rápida formação de trabéculas novas nessa região. Tal fato não ocorreu de forma tão pronunciada nas regiões proximal e distal provavelmente por serem locais de predominância de osso cortical.

Foram observadas projeções dos tecidos ósseo e conjuntivo para o interior do compósito, o que reforça o caráter biocompatível deste. Além disso, demonstra que o compósito auxilia o desenvolvimento tecidual, permitindo a migração de células produtoras de novo osso dentro de seus poros e a fixação delas nestes locais, ou seja, osseocondução (Borges et al., 2000; Sá et al., 2007).

No grupo-controle, aos 45 dias, observou-se tecido ósseo trabecular mais organizado na região medial ao defeito, com trabéculas mais espessas e menos numerosas. Aos 90 dias, a arquitetura tecidual já se encontrava restabelecida, com osso trabecular organizado no centro do defeito e a cortical lateral do olécrano formada.

Aos 45 e 90 dias, no grupo HP, o processo de regeneração associado ao compósito se deu de forma muito semelhante ao das amostras do grupo-controle. Tal fato já foi comprovado para a hidroxiapatita pura, passando pela neovascularização, diferenciação de células osteoprogenitoras, formação de novo osso e remodelação óssea (Borges et al., 2000; Walsh et al., 2003; Duarte et al., 2006). Tecido ósseo trabecular organizado predominava na interface com o compósito, associado à medula óssea (Fig. 1B e 1C). Foram observadas trabéculas no interior do compósito (Fig. 1B, 1C e 1D) e também tecido conjuntivo frouxo e vasos sanguíneos. Osteoclastos encontravam-se na interface do tecido ósseo com o compósito, invaginando na direção deste último. Essas células também foram observadas na interface trabéculas-compósito (Fig. 1C e 1D) de forma semelhante ao túnel de reabsorção formado na remodelação óssea (Yamamuro, 1994). Portanto, a formação de novo osso na interface com o compósito é morfologicamente comparável a locais de remodelação óssea normais, o que está de acordo com os achados de Doyle et al. (1991) e Luklinska e Bonfield (1997).

Nas bordas proximal, distal e medial ao defeito, puderam-se observar, aos 45 e 90 dias, fragmentos do compósito separados do bloco original em meio ao tecido ósseo adjacente (Fig. 1F), semelhante ao relatado por Sá et al. (2007) com a associação de hidroxiapatita e zircônia. Assim como observado por Luklinska e Bonfield (1997) e Shishatskaya et al. (2006), pode-se sugerir uma progressão de acontecimentos: migração celular por poros já existentes no material e formação de novo osso englobando fragmentos do compósito, ou seja, osseointegração e osseocondução. Estes, então, separam-se do bloco original, ocorrendo também a biodegradação, com a formação de novos poros e gradual substituição do biomaterial. 


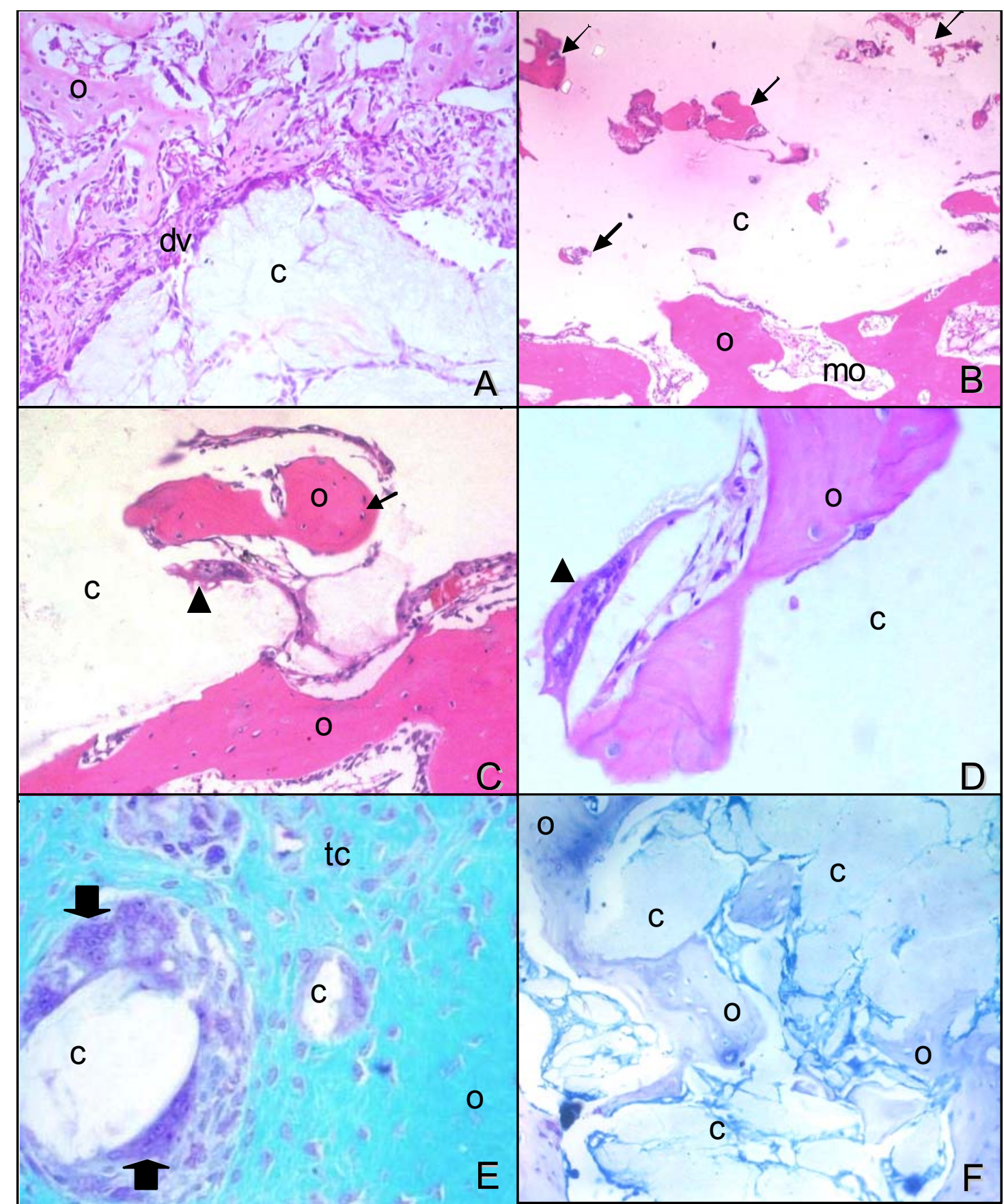

Figura 1. Fotomicrografias de regiões do defeito ósseo no olécrano de coelho após implantação de compósito de hidroxiapatita e poli-hidroxibutirato. A- Aos oito dias, tecido ósseo (o) trabecular menos organizado em meio ao tecido conjuntivo denso vascularizado (dv) em contato com compósito (c). HE, 200X. B- Aos 45 dias as trabéculas (setas) no interior do compósito, próximas à região medial ao defeito, com osso trabecular mais organizado (o) do que aos oito dias e medula óssea (mo). HE, 100X. C- Projeção (seta) de tecido ósseo para o interior do compósito, aos 45 dias. Notar osteoclasto (ponta de seta) na interface entre osso e compósito. HE, 200X. D- Trabécula óssea no interior do compósito com osteoclasto (ponta de seta) na interface, aos 90 dias. HE, 400X. E- Células gigantes (setas largas) envolvendo fragmento de compósito na transição entre tecidos conjuntivo e ósseo, aos 45 dias. Notar a ausência de infiltrado inflamatório. HE, 400X. F- Aos 45 dias, fragmentos do compósito separados do bloco original envolto por tecido ósseo. Notar o contato direto entre osso e compósito. AT, 200X. 
Fragmentos de hidroxiapatita e polihidroxibutirato também foram observados no tecido que envolveu a região lateral ao compósito e continuava com o tecido ósseo adjacente. Eles eram numerosos e estavam associados a um tecido mesenquimal com grande número de células blásticas, discretas formações de matriz osteoide e células gigantes ao redor destes fragmentos (Fig. 1E). A presença de matriz osteoide sugere a formação de tecido ósseo neste local. Já as células gigantes são responsáveis pela degradação de material e restos teciduais em locais de reparação (Volova et al., 2003; Rumpel et al., 2006). Dessa forma, as características aqui observadas sugerem processo de biodegradação do compósito. Estes achados estão de acordo com os de Volova et al. (2003), que observaram a influência de enzimas da matriz extracelular dos tecidos, macrófagos e células gigantes na degradação de fibras de PHB. Eles observaram erosão na superfície do PHB, sem reações adversas como inflamação supurativa, necrose ou calcificação de tecido fibroso. Também condizem com Borkenhagen et al. (1998), ao estudarem sistemas guias para regeneração de nervos, constituídos de diferentes proporções de PHB e poli-hidroxivalerato. Observaram perda de peso de até $88 \%$ e macrófagos e células gigantes associados aos sistemas, que não interferiram no processo. Borges et al. (2000) e Rumpel et al. (2006) relataram a presença dessas células sobre os grânulos de hidroxiapatita em processo de biodegradação, semelhante ao processo natural de reabsorção do tecido ósseo, sugerindo sua completa biodegradação durante a remodelação óssea.

Não é apropriado comparar histomorfometricamente o grupo-controle com o grupo tratado, porque significaria avaliar a eficiência do compósito na regeneração de um defeito de tamanho não-crítico. Sabe-se que a utilização de substitutos ósseos só é indicada onde não é possível que a regeneração ocorra sem sua ajuda, ou seja, defeitos de tamanho crítico, o que no coelho está próximo de $15 \mathrm{~mm}$ (Macneill et al., 1999). Avaliar as características de osseointegração e a osseocondução de um biomaterial em defeitos de tamanho crítico poderia levar a falsos resultados, visto que essas características sofrem influência de outros fatores além do biomaterial, como o dispositivo utilizado para fixação e a estabilidade do implante (Macneill et al., 1999; Boer et al., 2003). Portanto, à análise histomorfométrica, comparou-se a formação de tecido ósseo, o desejado, com a do tecido conjuntivo. Pode-se notar que, nos dias oito, 45 e 90, o percentual de tecido ósseo foi significantemente maior do que o de tecido conjuntivo (Tab. 1). Além disso, aos 90 dias, o percentual de tecido ósseo foi maior do que aos oito dias (Tab. 1). Percebe-se, assim, que a presença dos compósitos não afetou negativamente o desenvolvimento do tecido ósseo. Na interface, o percentual de tecido ósseo foi significantemente maior do que o de tecido conjuntivo aos 45 e 90 dias (Tab. 2), indicando a osseointegração do compósito, o que pode ser um reflexo da bioatividade da HAP-91 ${ }^{\circledR}$ (Borges et al., 2000; Scarano et al., 2006). Analisando-se a formação de tecidos no interior do compósito, observou-se que a proporção de tecido ósseo aos 90 dias $(7,6 \% \pm 8,3)$ foi significantemente maior do que aos oito dias $(0,5 \% \pm 1,4)$, sendo que a própria presença destes tecidos dentro dos poros do biomaterial confirma sua osseocondutividade (Borges et al., 2000; Scarano et al., 2006). Não existiram diferenças significantes no número de osteoclastos entre os grupos, mas, entre oito e 90 dias, foram observadas diferenças significantes em ambos os grupos (Tab. 3). Esses dados reforçam que o compósito não interfere negativamente no desenvolvimento do tecido ósseo ao demonstrar uma evolução semelhante ao grupo-controle.

Tabela 1. Médias e desvios-padrão das porcentagens de tecido ósseo e tecido conjuntivo formados nos defeitos ósseos experimentais na ulna de coelhos aos oito, 45 e 90 dias após a implantação de compósitos contendo $50 \%$ de HAP- $91^{\circledR}$ e $50 \%$ de poli-hidroxibutirato

\begin{tabular}{ccc}
\hline Dia & Tecido ósseo & Tecido conjuntivo \\
\hline 8 & $57,7 \pm 6,9 \mathrm{a}^{*}$ & $5,3 \pm 9,1 \mathrm{~b}$ \\
45 & $50,7 \pm 7,3 \mathrm{a}$ & $0 \mathrm{~b}$ \\
90 & $38,3 \pm 12,9 \mathrm{a}^{*}$ & $0,2 \pm 0,4 \mathrm{~b}$ \\
\hline
\end{tabular}

Letras diferentes na mesma linha sinalizam diferença entre valores pelo teste Mann-Whitney $(\mathrm{P}<0,05)$.

* Indica única diferença significante entre os dias, pelo teste Kruskal-Wallis $(\mathrm{P}<0,05)$. 
Tabela 2. Médias e desvios-padrão das porcentagens de tecido ósseo e tecido conjuntivo formados na interface com compósitos contendo $50 \%$ de HAP- $911^{\circledR}$ e $50 \%$ de poli-hidroxibutirato, aos oito, 45 e 90 dias após a implantação em defeitos ósseos experimentais na ulna de coelhos

\begin{tabular}{ccc}
\hline Dia & Tecido ósseo & Tecido conjuntivo \\
\hline 8 & $45,1 \pm 27,7 \mathrm{a}$ & $43,2 \pm 34,3 \mathrm{a}$ \\
45 & $79,4 \pm 8,9 \mathrm{a}$ & $4,3 \pm 3,7 \mathrm{~b}$ \\
90 & $66,9 \pm 9,2 \mathrm{a}$ & $20,0 \pm 13,6 \mathrm{~b}$ \\
\hline
\end{tabular}

Letras diferentes na mesma linha sinalizam diferença entre valores pelo teste Mann-Whitney $(\mathrm{P}<0,05)$.

Tabela 3. Médias e desvios-padrão do número de osteoclastos presentes nos defeitos ósseos na ulna de coelhos aos oito, 45 e 90 dias após a cirurgia com implantação ou não (grupo-controle) de compósitos contendo $50 \%$ de HAP- $91{ }^{\circledR}$ e $50 \%$ de poli-hidroxibutirato

\begin{tabular}{ccc}
\hline Dia & $\mathrm{C}$ & HP \\
\hline 8 & $27,7 \pm 3,5 \mathrm{aA}$ & $25,5 \pm 9,1 \mathrm{aA}$ \\
45 & $10,7 \pm 11,5 \mathrm{aAB}$ & $8,7 \pm 7,6 \mathrm{aAB}$ \\
90 & $1,3 \pm 1,5 \mathrm{aB}$ & $5,8 \pm 6,1 \mathrm{aB}$ \\
\hline
\end{tabular}

Letras minúsculas distintas na mesma linha e letras maiúsculas distintas na mesma coluna indicam diferença significante entre valores pelo teste Kruskal-Wallis $(\mathrm{P}<0,05)$.

\section{CONCLUSÕES}

Com base nos resultados obtidos e nas condições deste experimento, pode-se concluir que o compósito de $50 \%$ HAP-91® e $50 \%$ polihidroxibutirato é biocompatível, osseocondutor, integra-se ao tecido ósseo e é degradado in vivo.

\section{AGRADECIMENTOS}

Os autores agradecem à Dra. Sheyla M. C. M. Bicalho, da JHS Laboratório Químico - MG e ao Prof. Paulo Miranda Oliveira, pelo apoio e fornecimento do material. Também agradecem à CAPES, pela bolsa de mestrado da Emily Correna Carlo.

\section{REFERÊNCIAS BIBLIOGRÁFICAS}

BOER, F.C.; WIPPERMANN, B.W.; BLOKHUIS, F.J. et al. Healing of segmental bone defects with granular porous hydroxyapatite augmented with recombinant human osteogenic protein-1 or autologous bone marrow. J. Orthop. Res., v.21, p.521-528, 2003.

BORGES, A.P.B.; REZENDE, C.M.F.; RIBEIRO, M.F.B. et al. Hidroxiapatita sintética como substituto ósseo em defeito experimental provocado no proximal da tíbia de cão: aspectos à microscopia de transmissão. Arq. Bras. Med. Vet. Zootec., v.52, p.616-620, 2000.

BORKENHAGEN, M.; STOLL, R.C.; NEUENSCHWANDER, $\mathrm{P}$. et al. In vivo performance of a new bidegradable polyester urethane system used as a nerve guidance channel. Biomaterials, v.19, p.2155-2165, 1998.

BRANDÃO, A.C.; BRENTEGANI, L.G.; NOVAES, A.B. et al. Histomorphometric analysis of rat alveolar wound healing with hydroxyapatite alone or associated to BMPs. Braz. Dent. J., v.13, p.147-154, 2002.

CHENG, S.; CHEN, G.Q.; LESKI, M. et al. The effect of d,1-2hydroxybutyric acid on cell death and proliferation in L929 cells. Biomaterials, v.27, p.3758-3765, 2006.

DOYLE, C.; TANNER, E.T.; BONFIELD, W. In vitro and in vivo evaluation of polyhydroxybutyrate and of polyhydroxybutyrate reinforced with hydroxyapatite. Biomaterials, v.12, p.841-847, 1991.

DUARTE, T.S.; BORGES, A.P.B.; LAVOR, M.S.L. et al. Osteointegração da hidroxiapatita sintética no processo alveolar da mandíbula de cães: aspectos histológicos. Arq. Bras. Med. Vet. Zootec., v.58, p.849-853, 2006.

KLEINER, J.A.; SILVA, E.G. Tumores ósseos em pequenos animais. MedVep, 2003. Disponível em: <http://www.vetweb.com.br $>$. Acessado em: 3 jul. 2007.

KNOWLES, J.C.; HASTINGS, G.W.; OHTA, H. et al. Development of a degradable composite for orthopaedic use: in vivo biomechanical of two bioactive degradable composites based on the polyhydroxybutyrate polymer. Biomaterials, v.13, p.491-496, 1992. 
LUKLINSKA, Z.B.; BONFIELD, W. Morphology and ultrastructure of the interface between hydroxyapatite-polyhydroxybutyrate composite implant and bone. J. Mat. Sci. Mat. Med., v.8, p.379-383, 1997.

MacNEILL, S.R.; COBB, C.M.; RAPLEY, J.W. et al. In vivo comparison of synthetic osseous graft materials. A preliminary study. J. Clin. Periodontol., v.26, p.239-245, 1999.

RUMPEL, E.; WOLF, E.; KAUSCHKE, E. et al. The biodegradation of hydroxyapatite bone graft substitutes in vivo. Folia Morphol., v.65, p.4348, 2006.

SA, M.J.C.; REZENDE, C.M.F.; SILVA JUNIOR, V.A. et al. In vivo behavior of zirconiahydroxyapatite $(\mathrm{ZH})$ ceramic implants in dogs: a clinical, radiographic, and histological study. $J$. Biom. Applic., v.22, p.5-31, 2007.

SCARANO, A.; DEGIDI, M.; IEZZI, G. et al. Maxillary sinus augmentation with different biomaterials: a comparative histologic and histomorphometric study in man. Implantol. Dent., v.15, p.197-207, 2006.
SHISHATSKAYA, E.I.; KHLUSOV, I.A.; VOLOVA, T.G. A hybrid PHB-hydroxyapatite composite for biomedical application: production, in vitro and in vivo investigation. $J$. Biom. Sci. Polymer Ed., v.17, p.481-498, 2006.

VITAL, C.; BORGES, A.P.B.; FONSECA, C.C. et al. Biocompatibilidade e comportamento de compósitos de hidroxiapatita em falha óssea na ulna de coelhos. Arq. Bras. Med. Vet. Zootec., v.58, p.175-183, 2006.

VOLOVA, T.; SHISHATSKAYA, E.; SEVASTIANOV, V. et al. Results of biomedical investigantions of $\mathrm{PHB}$ and $\mathrm{PHA} / \mathrm{PHV}$ fibres. Bioch. Eng. J., v.16, p.125-133, 2003.

WALSH, W.R.; SHEATH, P.J.C.; CAIN, S. et al. A resorbable porous ceramic composite bone graft substitute in a rabbit metaphyseal defect model. J. Orthop. Res., v.21, p.655-661, 2003.

YAMAMURO, T. Bone bond behavior and clinical use of A-W glass-ceramic. In: URIST, M.M.; O'CONNOR, B.T.; BURWELL, R.G. (Eds.). Bone grafts derivate and substitutes. Cambridge: Butterworth-Heinemann, 1994. p.245-259. 